\title{
Selection of Appropriate Media and Technology for Distance Education
}

\author{
Dr. Eng. Wassan Adnan Hashim ${ }^{1}$, Hala A. Hashim² \\ ${ }^{1}$ Bayan University, Computer Science, Goulan Road, Erbil, Iraq \\ ${ }^{2}$ Dejla University, Dora, Baghdad, Iraq
}

\begin{abstract}
The technology has revolutionized the world of education. The role of teachers has been changed from merely delivering information to guiding students in their discovery of knowledge. Innovative technologies have enhanced distance learning. The term distance education has been applied to a tremendous variety of programs serving numerous audiences via a wide variety of media. Distance education is one of the tools that promises to remove the barrier of geographic location, because it increases time and place flexibility, provides just-in-time learning, reduces costs, and has quicker time development than traditional material development. The technologies used for distance education fall into two categories: telecommunications technologies that connect instructors to distant learners and classroom technologies that record, present, and display instructional information. Communicating with someone via the right communication media seems to be difficult nowadays as people use various mode of communication media and senders do not have any knowledge about receivers' current communication media, especially in ubiquitous environment. Thus, we propose the method how the most appropriate media to reach the receiver can be selected based on the effective measures. Also, it's describes common media selection models and suggests strategies for the design of media combinations for a better learning. Indeed, the paper is concluded with the media design implementation in a distance education and showed some questions to consider when selecting media such as- how accessible is a particular technology for learners?; what are the best technologies for supporting this teaching and learning. The result is information and decision-making model that assists in the selection of appropriate teaching technologies to enhance student learning
\end{abstract}

Keywords: blended learning, design, distance education, media selection, technology.

\section{Introduction}

We are living in an ever-changing world". [1]. Through the past decades, the world of education has been varied by the fast and rapid revolution in computer and the Internet technologies which according to Sethy (2008: 29) -new findings are generated and become established at breathtaking speed". This has revolutionized teaching and learning particularly distance education.

Generally, Distance learning and education, is a field of education that focuses on technology and instructional systems design incorporated in delivering education to students who are NOT physically "on site" to receive their education. The historical evolution of distance education has been in four main phases, each with its own organizational form derived from the main form of communication. These are in summary Correspondence systems are originated at the end of the 19th Century, and is still the most widely used form of distance education in less developed countries. Based around a study guide in printed text and often accompanied by audio and video components such as records and slides, interaction in the correspondence method is by letters and other written or printed documents sent through postal systems [2].

Another advantage of distance education is that it can provide students with the opportunity to move through course material at a self-set pace, which increases meaning for them. If students are able to construct their own meaning, the content will be more relevant. An advantage of using modalities such as chat rooms and e-mail aids students who are apprehensive about participating in large-group settings.
These no threatening environments allow those students to be less self-conscious and more apt to participate and communicate their ideas and questions [3]. The process of selecting media for learning at a distance is, in most cases, the same (or nearly the same) as media selected for face-toface teaching and learning. Delivery of media online offers easy access for students who are located at home, in a place of work or using computer access points in schools and libraries. Selecting media for distance education begins with consideration of course (or unit) objectives as a starting point.

Each medium should pass certain tests before incorporating it into the distance learning scheme. Will the learner have access to the medium at home, work or in a community setting? Does the access include the necessary software? Can the cost of the material be justified, that is, is it cost effective for the instructor to produce and for the students to acquire? Is the resource essential or just "nice to have"? Again, think about cost to the student and the extent to which it will enhance achievement of the learning objectives.

In order to understand new coming technology and media, distance education researchers so often run media comparison studies. They mainly ask research questions such as Which media or technology is better for learning?" or What media or technology type is superior to traditional learning?" or Is a new media or technology is really working better than others?" or which media type has superiority to others or if one new media (and related technologies) type shows more benefits than the others?" In many articles researchers; who are discussing the media; try to answer these questions. They want to if a specific media type works 


\section{International Journal of Science and Research (IJSR) \\ ISSN (Online): 2319-7064 \\ Index Copernicus Value (2013): 6.14 | Impact Factor (2014): 5.611}

properly and if this media have some significant learning outcomes over the students learning [4].

\section{What is Distance Education}

This section offers a review of the literature related to the reasons new teachers leave the profession and potential solutions for supporting them, challenges in facing the unknown, the principal's role in supporting new teachers, and support strategies in recruitment, welcoming, mentoring and professional development. The term distance education (DE) refers to teaching and learning situations in which the instructor and the learner or learners are geographically separated, and therefore, rely on electronic devices and print materials for instructional delivery. Distance education includes distance teaching - the instructor's role in the process - and distance learning - the student's role in the process.

Although distance education certainly depends on communication technology it is much more than just technology. Rather it is a total DELIVERY system; it can be defined as:

-.. planned learning that normally occurs in a different place from teaching and as a result requires special techniques of course design, special instructional techniques, special methods of communication by electronic and other technology, as well as special organizational and administrative arrangements" [5].

Figure 1 presents a timeline of distance learning, Figure 2 traces the - genealogy of distance learning by depicting its early origins to the application of communication media (technology enabled) to computer mediated and electronically assisted learning throughout the past 120 years
[6]. For an activity to be considered distance education it should include — at minimum — the following [7]:

Physical distance between the student and the teacher - the most obvious element

An organization that provides the content - in contrast to purely self-directed learning

A curriculum - learning must have an objective and therefore must have structure

Measurement of learning - without which no learning can be observed to have taken place

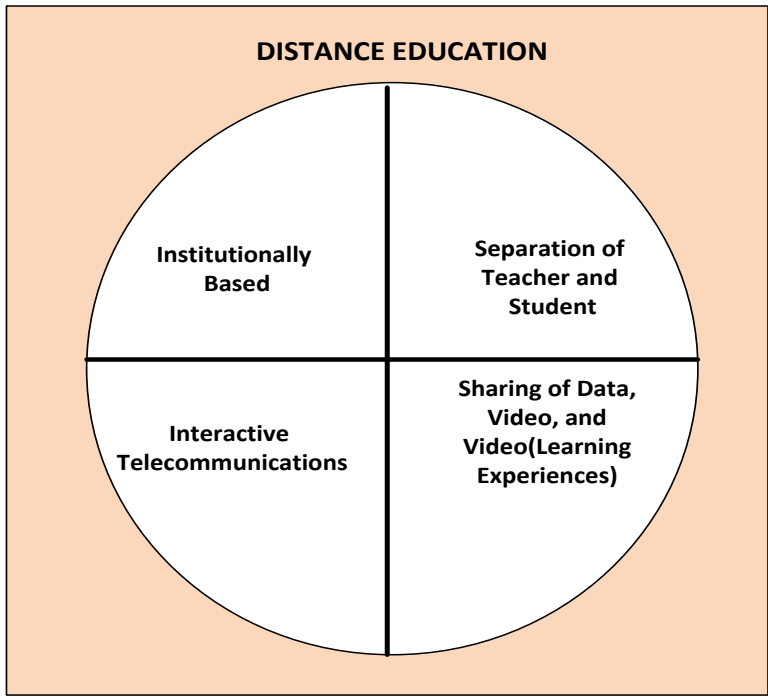

Figure 1: A timeline of Distance Learning [6]

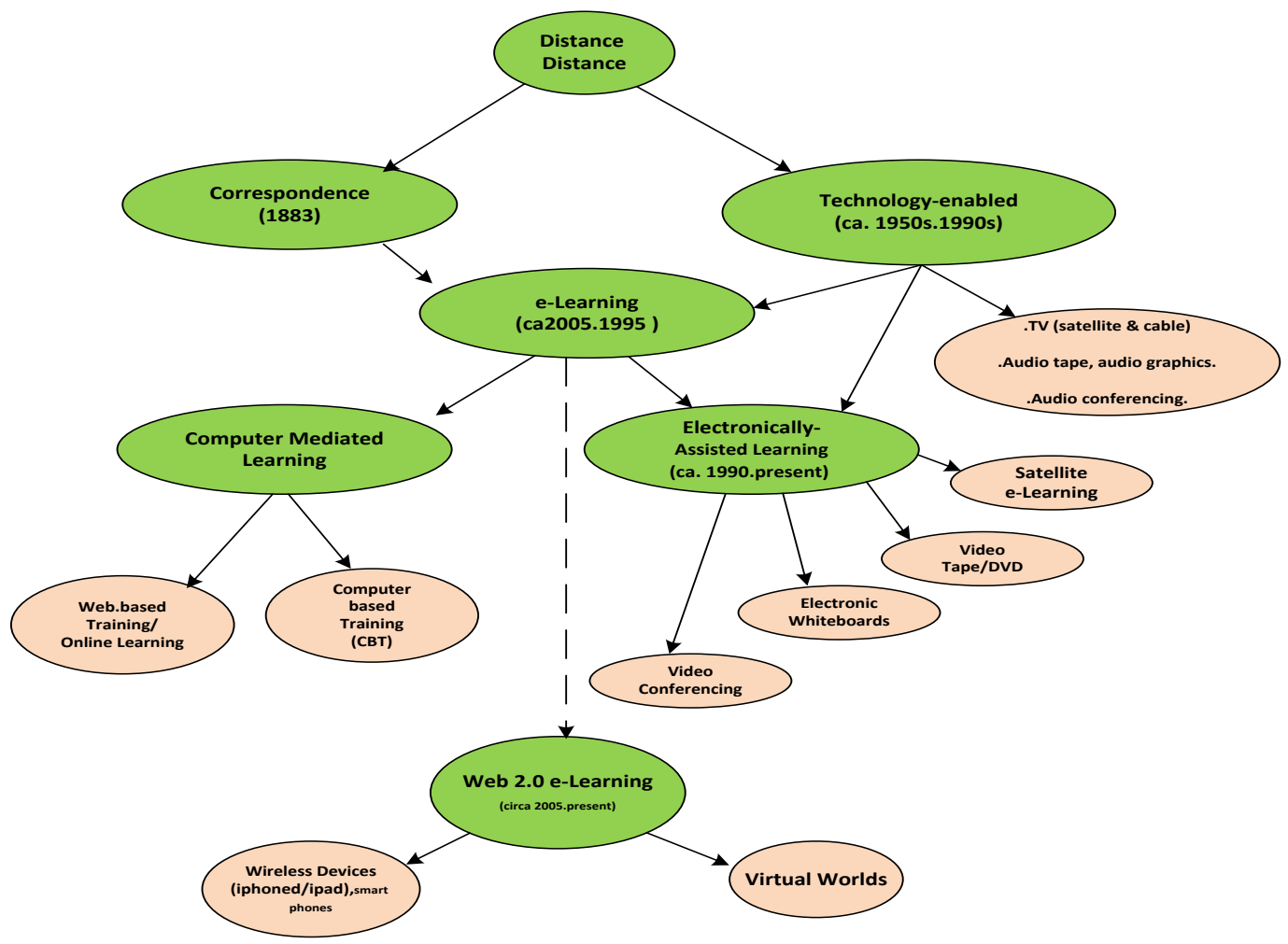

Figure 2: Traces the -Genealogy of Distance Learning [7] 


\section{International Journal of Science and Research (IJSR) \\ ISSN (Online): 2319-7064}

Index Copernicus Value (2013): 6.14 | Impact Factor (2014): 5.611

\section{Types of Media and Technologies in Distance Education}

According to Bates, -medium is a form of communication associated with particular ways of representing knowledge". Every media presents knowledge and/or information differently. However, each new medium makes the media selectors' job harder. How should educators and trainers go about selecting media? A number of media selection models have been developed in an attempt to answer this question. In the 1970s to 1980s there was a rapid development of media selection models. Since the designing of media selection models was nearly simultaneous, according to Romiszowski (1988), there are many similarities among the models. Some of the main differences, however, between these models are the methodology of task analysis to define the instructional objectives of the lesson, and the instrumentation and type of job aids used in the selection process

\subsection{Media Selection Models}

Media selection analysis must evaluate general and specific criteria, including instructional, student, and cost aspects for each delivery technology (or instructional medium) to ensure that the most appropriate media are selected for specific education or training objective. Tony Bates's ACTIONS model is one of the clearest criteria for selection of media (Bates, 1995). ACTIONS is an acronym for access, costs, teaching and learning, interactivity and user-friendliness, organizational issues, novelty, and speed. Table 1 shows Bates's ACTIONS model for selecting media[8]

The methods of presenting knowledge and the types of media in distance education are [9]:

- Textual presentation $\rightarrow$ worded media (printed material)

- Audio presentation $\rightarrow$ sonic media

- Video presentation $\rightarrow$ video media

- Computer presentation $\rightarrow$ combined media and multimedia

Table 1: Bates's ACTIONS model for selecting Media [8].

\begin{tabular}{|c|c|}
\hline Accessibility & $\begin{array}{l}\text { Is the equipment your program requires available to the learners? Where will they be learning? At home? In the } \\
\text { workplace? At a learning center? }\end{array}$ \\
\hline Cost & $\begin{array}{l}\text { Are the costs of production, delivery, and maintenance using this technology affordable? Are the costs } \\
\text { appropriate to the number of learners who will be enrolled? }\end{array}$ \\
\hline Teaching ability & $\begin{array}{l}\text { Does the technology convey the level of facts, attitudes and skills your program requires? Is it suited to the } \\
\text { kinds of learning required? }\end{array}$ \\
\hline $\begin{array}{l}\text { Interactivity and user- } \\
\text { friendliness }\end{array}$ & Is the technology user -friendly? Can it convey adequate and timely feedback to the learner? \\
\hline Organization & How open is your organization to change and the introduction of new media \\
\hline Novelty & Is it important to your organization to be leading edge"? Is this a technology that learners will want to try? \\
\hline Speed & $\begin{array}{l}\text { How fast can your program implement this technology? How much training do staff and students need in order } \\
\text { to be able to use it? Will its use enable you to revise your materials as quickly as you need to? }\end{array}$ \\
\hline
\end{tabular}

No one aspect of the media is more effective or more suitable than another. The combinations of media used define the quality of the presented study material. An appropriate media for distance education must have the following criteria:

1)Media, which can be used by all students and to which they have assured access.

2)Adaptability, which means that the media can be used in the place and in at the time best suited to the student.

3)Media, which enables a student's active participation in distance education.

4)Possibility to connect any particular media with others, thus enabling an assessment of the nonverbal diction of the distance education participants to take place.

This communication process between participants in distance education simulates near reality. At the same time geographic and time differences in their communication becomes insignificant during the study process.

\subsection{The role of technologies in distance education}

That it is to enable the media activity and to enable the transmission and presentation of knowledge and information. There are several technologies that enable media activity such as: Audio presentation of knowledge can be performed using audiocassettes, radio and telephone. Video presentation can be performed using television transmission, videocassettes, CD-ROM, satellite transmission, cable transmission, microwaves a) One way transmission: These technologies do not enable student interaction, which means that the student is a passive participant in distance education These kinds of technologies are radio and television

b) Tow way transmission: These technologies enable student interaction, which means that the student is an active participant in distance education. These kinds of technologies are videoconference, computer communication and interactive television.

In regard to the time differences in communication between the student and the teacher or among students, the technologies that enable two-way transmission of information can be:

- Asynchronous (time-delayed") - technologies where the teacher or the student can take part in the communication process whenever they wish. For example: e-mail.

- Synchronous ("real-time") - technologies where the teacher or the student takes part in the process of communication in stantaneously at the time of communication, where there are no time differences between the information and return information. For example: teleconference, chat-room and telephone. Table 2 show Distance education technologies in regard to time and place 


\section{International Journal of Science and Research (IJSR) \\ ISSN (Online): 2319-7064}

Index Copernicus Value (2013): 6.14 | Impact Factor (2014): 5.611

Table 2: Distance Education Technologies in regard to Time and Place[9]

\begin{tabular}{|c|c|c|c|}
\hline & \\
\hline & & \multicolumn{2}{|c|}{ PLACE } \\
\hline \multirow{7}{*}{ TIME } & & The same & Different \\
\hline & \multirow{3}{*}{ The same } & \multicolumn{2}{|c|}{ Synchronous technologies } \\
\hline & & $\begin{array}{c}\text { Interaction assured- } \\
\text { example: study } \\
\text { material projecting } \\
\end{array}$ & $\begin{array}{l}\text { Interaction assured- } \\
\text { example: teleconference, } \\
\text { telephone. }\end{array}$ \\
\hline & & & $\begin{array}{c}\text { Interaction not assured } \\
\text { - example: television, } \\
\text { radio,.. }\end{array}$ \\
\hline & \multirow[b]{3}{*}{ Different } & \multicolumn{2}{|c|}{ Asynchronous technologies } \\
\hline & & \begin{tabular}{|c|} 
Interaction assured- \\
example: electronic \\
mail, WBT, ...
\end{tabular} & $\begin{array}{c}\text { Interaction assured- } \\
\text { example: electronic mail, } \\
\text { newsgroups, WBT, ... }\end{array}$ \\
\hline & & $\begin{array}{l}\text { Interaction not } \\
\text { assured } \\
\text { - example: } \\
\text { video, audio } \\
\text { recordings }\end{array}$ & $\begin{array}{l}\text { Interaction not assured } \\
\text { example: printed material, } \\
\text { video and audio } \\
\text { recordings, CDs, DVDs }\end{array}$ \\
\hline
\end{tabular}

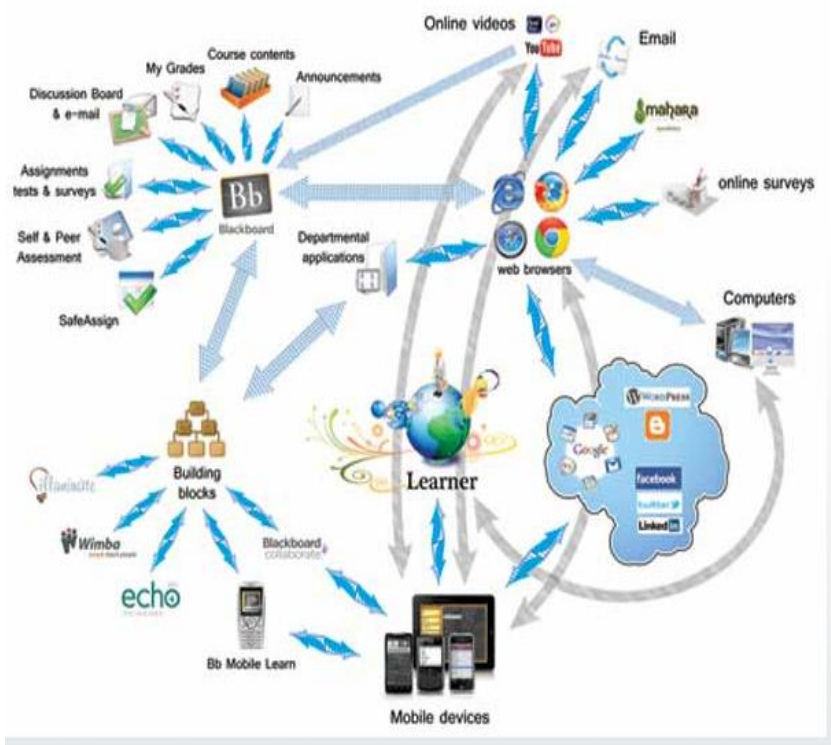

Figure 3. Technical Environment [9]

\section{Proposed Measures for Media Selection}

First, we define the availability measure to guess which media is currently being used by the user. Secondly, we define the user preference measure to specify the available media as there may be more than one available media for the recipient. Finally, we define the stability measures to know whether the media, which can be considered as available and preferred by user, is stable or not[10],[11].

4.1 Availability (A): availability A can be defined how much the media of the receiver is currently in active i.e. which device is currently being used by the receiver.

4.2 User Preference (P): user preference $\mathrm{P}$ can be defined as the particular media which is frequently used by the user. To calculate user preference we need to maintain user's call history. User preference can be calculated as follows:

$$
\mathrm{P}=\frac{\text { No, of usage for each media }}{\text { No. of total usage for all available media }}
$$

4.3 Stability (S): stability S can be defined as a measure that describes how many calls are connected during the certain period of time $\mathrm{T}$ (e.g. $\mathrm{T}=10$ minutes). We can calculate the stability value as follows.

$$
S=\frac{\text { No. of connected calls within time } T}{\text { No. of total incoming calls within Time } T}
$$

This stability equation would be considered for the synchronous communication media. For the asynchronous communication media such as email and IM, the stability measure would not be calculated

\section{Instructional Media for Distance Education}

The adoption of appropriate instructional media can also be seen as an effective way to ensure learners' independence where greater responsibility for learning is placed on the learners. As instructional designers of distance education courses or programs, it is important to know the strengths and weaknesses of instructional media for distance education. It is important also that we take a system view of how instructional media technologies we choose impact all components of distance education delivery system [12].

\section{A Prototype for Communication Media Selection}

In the below prototype system, as shown in figure 5, the media selection component gets the information about the available media from user schedule, user log and profiles stored in database. Then the preferred and stable media is selected among the available media according to the algorithm. When the caller accesses the system with one of user contact information, the system will support the caller with the information of the best media to reach the receiver.

\section{The Latest Techniques Employed For Distance Learning}

\subsection{The Virtual Class Room System CENTRA ${ }^{1}$}

Virtual classrooms provide lectures on the Internet based on the smart classroom environment and essential elements needed by both teacher and student. One of the main instruments in the system of Open Interactive distance education, a technique that is the most advanced in the world and future training and education in general.

\section{a) The Features of Virtual Class Room System (CENTRA):}

- Live Interaction [Face to Face]: It enables the teacher to begin a Live open discussion by engaging various tools, such as Video and Virtual Whiteboard.

- Multipurpose Interactive Web pages can be saved for future referencing.

- Text Messaging and Screen shots.

- Voting by Yes /No, instant Surveys, Hand raising for answering, Text Chat and Voice Messaging. 


\section{International Journal of Science and Research (IJSR)}

ISSN (Online): 2319-7064

Index Copernicus Value (2013): 6.14 | Impact Factor (2014): 5.611

b)The System requirements for Virtual Class Room System (CENTRA):

- Personal Computer System [with Sound Card and Modem]

- Windows Operating System

- Web Browser

- Web Camera

- Speakers and Microphone

- CENTRA Client Program (The file available on Deanship of Distance Learning official web site.)

\subsection{The E-Learning Management Electronic System / EMES $^{2}$}

An integrated computer system that manages the educational process sensing where this system aims to facilitate the process of interaction between student and faculty member.

Since studies have shown that the best module for distance education is an example of the diverse methods and called Blended Learning. Where, the International Association for Online Learning, defines blended learning as -ombining online delivery of educational content with the best features of classroom interaction and live instruction to personalize learning, allow thoughtful reflection, and differentiate instruction from student-to-student across a diverse group of learners. This module requires the provision of management systems of distance education provides interaction between student and faculty article as shown in Figure 9.

\section{Conclusion}

Distance education is a kind of education in which teacher and learner are separated and instructional materials are carried through telecommunication systems. Many universities across the world have used this system of learning and have had successful experiences with it. While using distance education, there are limitations, strengths, and affecting variables that should be considered in advance. This paper presented the different factors and elements affecting the selection and use of instructional media in distance education from the learners' perspective. We have presented the prototype that can select the most appropriate communication media to reach the receiver. We have described the three effective measures- availability, user preference and stability.

The paper showed that in the design of distance education there is no one best instructional media. Usually to produce the best distance education courses a combination of instructional media is always the best approach to take in order to meet the learning objectives. The quality and effectiveness of distance learning are determined by instructional design and technique, the selection of appropriate technologies, and the quality of interaction afforded to learners

\section{References}

[1] Sethy, S.S., Đistance Education in the Age of Globalization: An Overwhelming Desire towards Blended Learning". Turkish Online Journal of Distance Education, 9 (3), 2008.

[2] Ugur DEMIRAY, Cases on Challenges Facing ELearning and National Development", Institutional Studies and Practices, vol1, Anadolu University, Eskisehir-Turkey, 2010.

[3] Alhalabi, B., Hamza, M., Marcovitz, D., \& Petrie, M., Remote Labs: An Innovative Leap In Engineering Distance Education", Paper presented at the IFAC/IEEE Symposium on Advances in Control Education, Gold Coast, Queensland, Australia, 2000

[4] Ilker Yengin, Adem Karahoca, Dilek Karahoca, Hüseyin Uzunboylu, Đeciding Which Technology is the Best for Distance Education": Issues in media/technology comparisons studies. Procedia Computer Science 3 (2011) 1388-1395, 2010

[5] Moore, M. G. \& Kearsley, G., Đistance Education: A Systems View", Boston, Wadsworth Publishing Company, 1996

[6] Michael Simonson, Sharon Smaldino, Michael Albright, Susan Zvacek, Feaching and Learning At A Distance Foundations of Distance Education", Fourth ed., ISBN13: 978-0-13-513776-5, from www.pearsonhighered.com, 2013

[7] Jolly T. Holden, Philip J.-L. Westfall, An Instructional Media Selection Guide for Distance Learning. $2^{\text {nd }}$ edition. Publisher, National distance learning week, United States Distance Learning Association USDLA, 2010

[8] Susan Lambert, Rhys Williams, A Model For Selecting Educational Technologies To Improve Student Learning", HERDSA Annual International Conference, Melbourne, 12-15 July,1999.

[9] Medeja Brglez, Matja Debevc, Ivan Gerliè, Brane Šmitek, Dean Korosec, Introduction to Organization of Distance Education". Faculty of Electrical Engineering and Computer Science, University of Maribor,2001

[10] Arafeh, S. (Ed.), The Implications of Information \& Communications Technologies for Distance Education: Looking Toward The Future", (Final Report). Retrieved from

http://www.sri.com/policy/csted/reports/sandt/it/Distanc e Ed_Lit_Review FINAL 6-9-04.pdf, 2004

[11] Tang, Y., Placing Theory Into Practice: An Exploration of Library Services to Distance Learners at Jacksonville State Universit", Journal of Library \& Information Services in Distance Learning, 3(34):p173-181. ERIC (EJ870594), 2009.

[12] Mario Eliezer Calixte, Instructional Media Selection and Usage in Distance Education Design”. Instructional Design for Distance Learning Professor Barbara Lockee, 2011

[13] Virtual Class Room System, user guided. From website http://centra.kau.edu.sa

[14] Website http://emes.kau.edu.sa 


\section{International Journal of Science and Research (IJSR) \\ ISSN (Online): 2319-7064}

Index Copernicus Value (2013): 6.14 | Impact Factor (2014): 5.611

Table 3. Asynchronous Instructional Media [12]

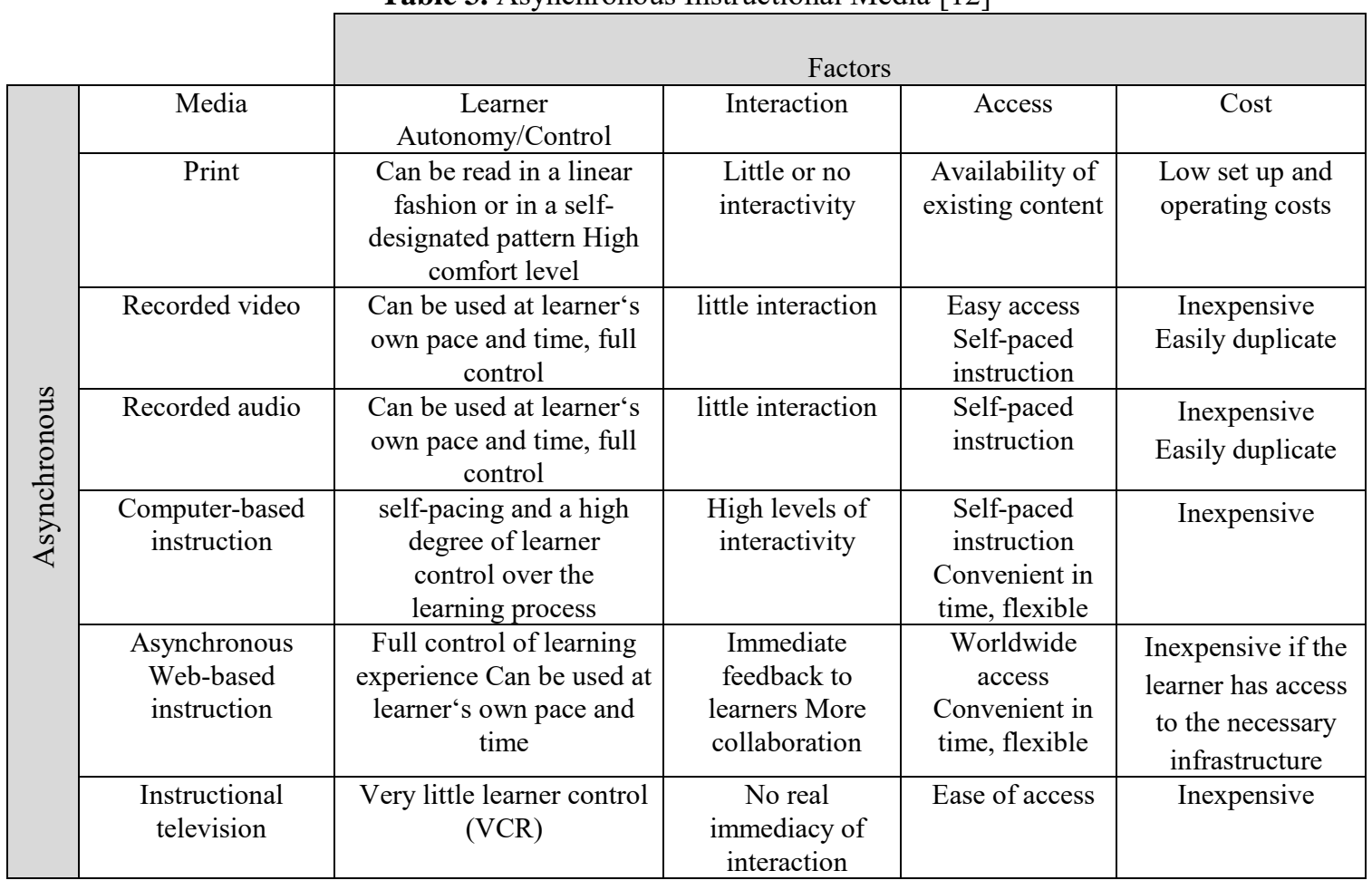

Table 4. Synchronous Instructional Media [12]

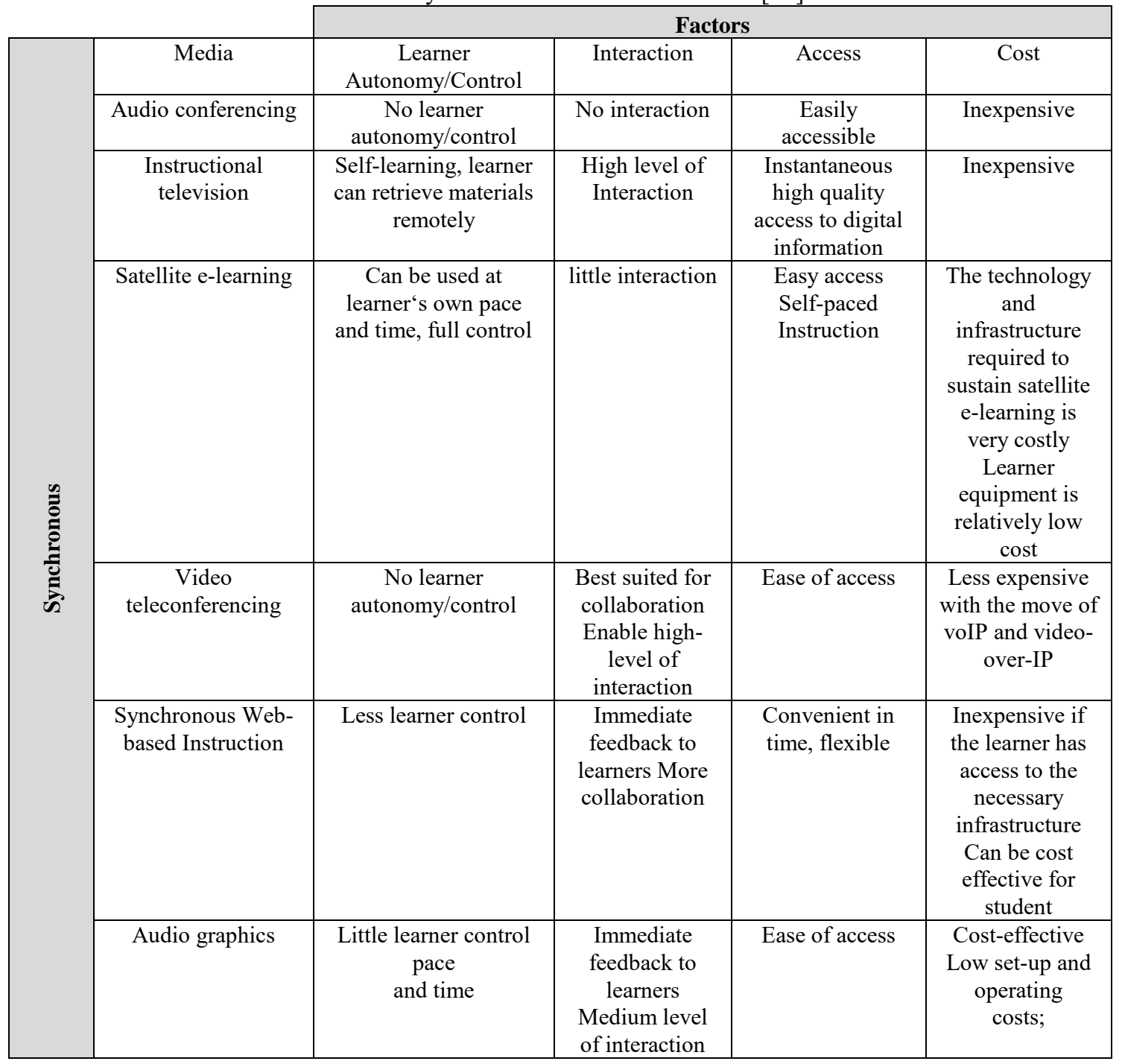




\section{International Journal of Science and Research (IJSR)}

ISSN (Online): 2319-7064

Index Copernicus Value (2013): 6.14 | Impact Factor (2014): 5.611

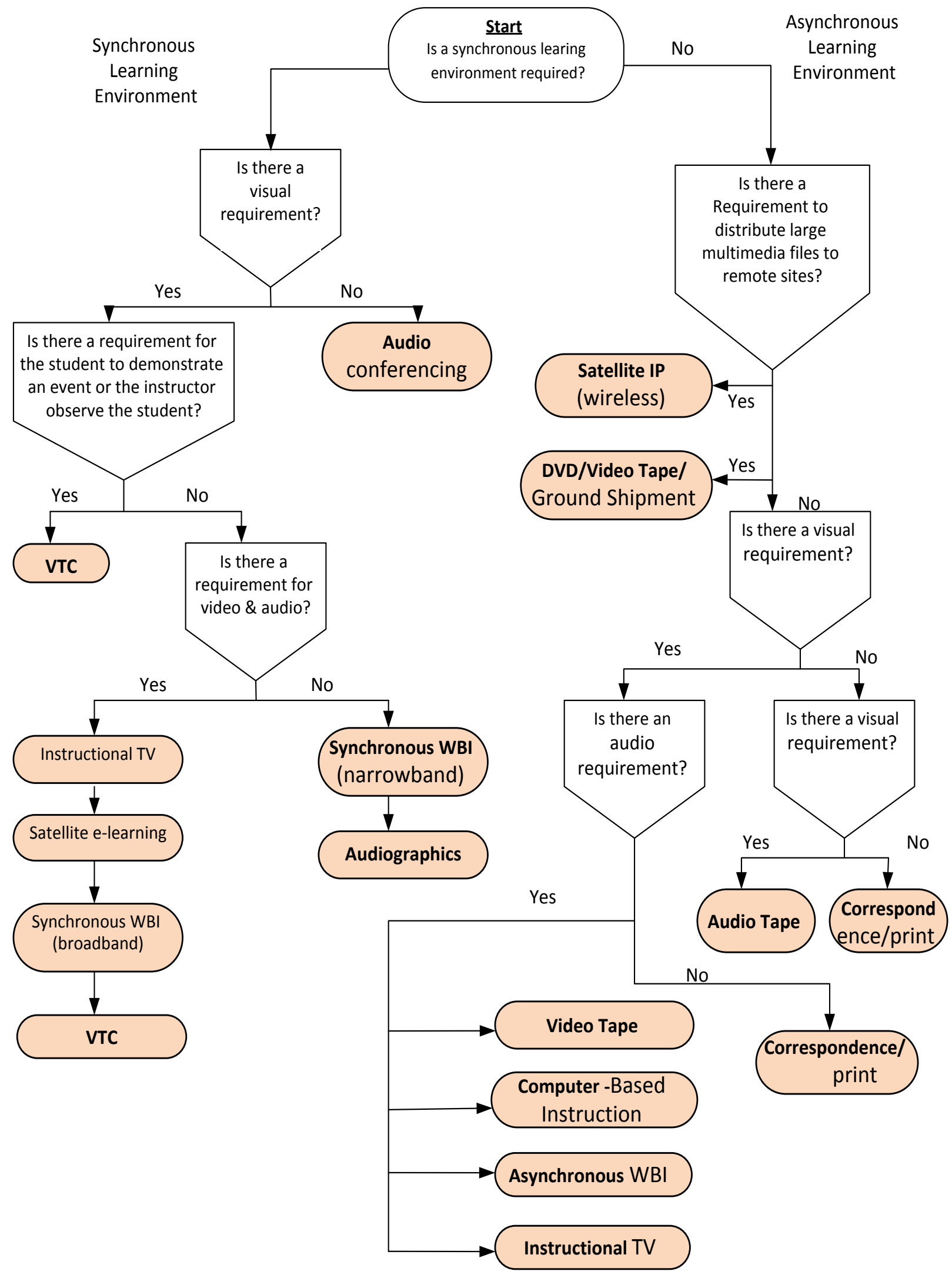

Figure 4: Distance Learning Instructional Media Selection Matrix [7] 


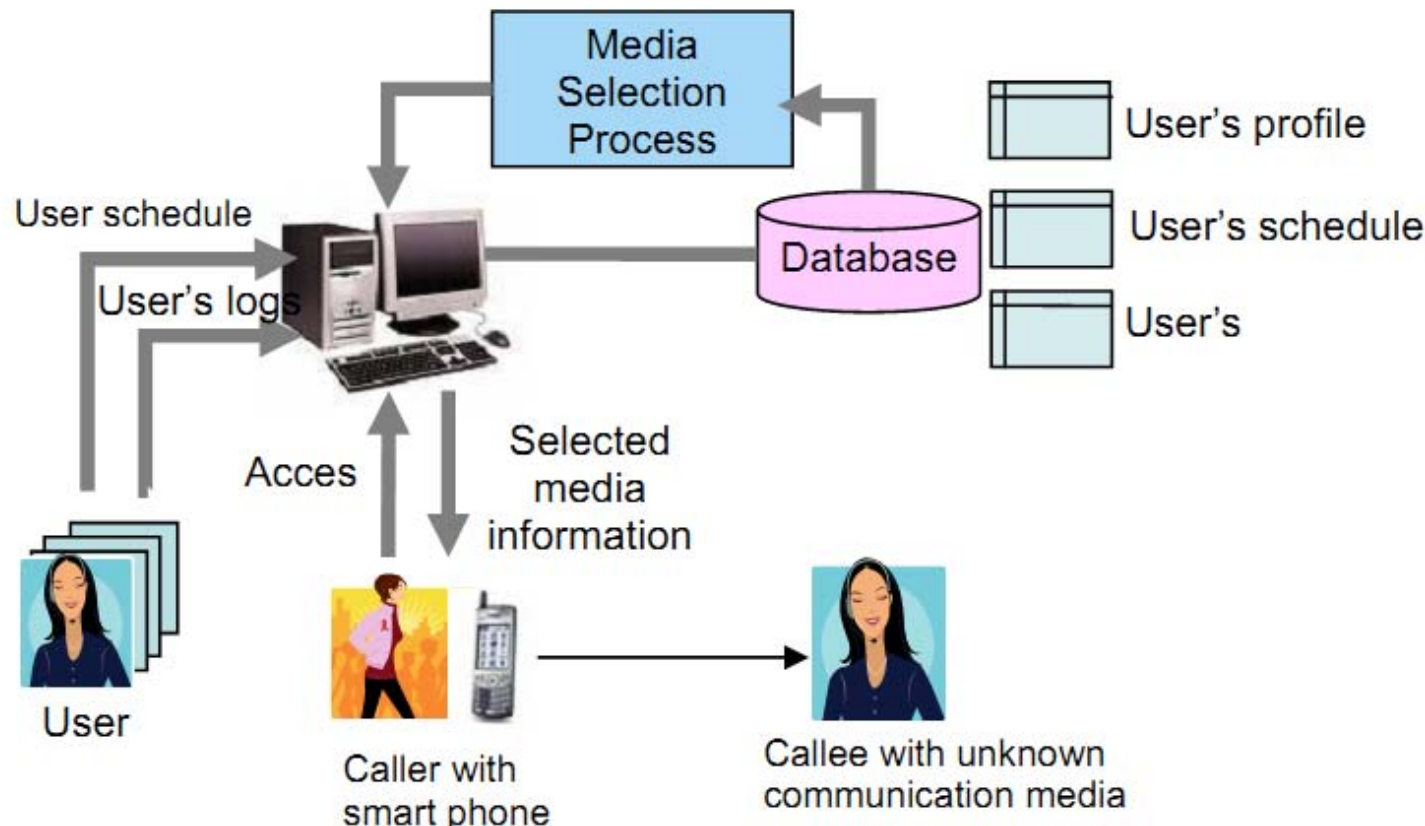

Figure 5: System architecture for communication media selection

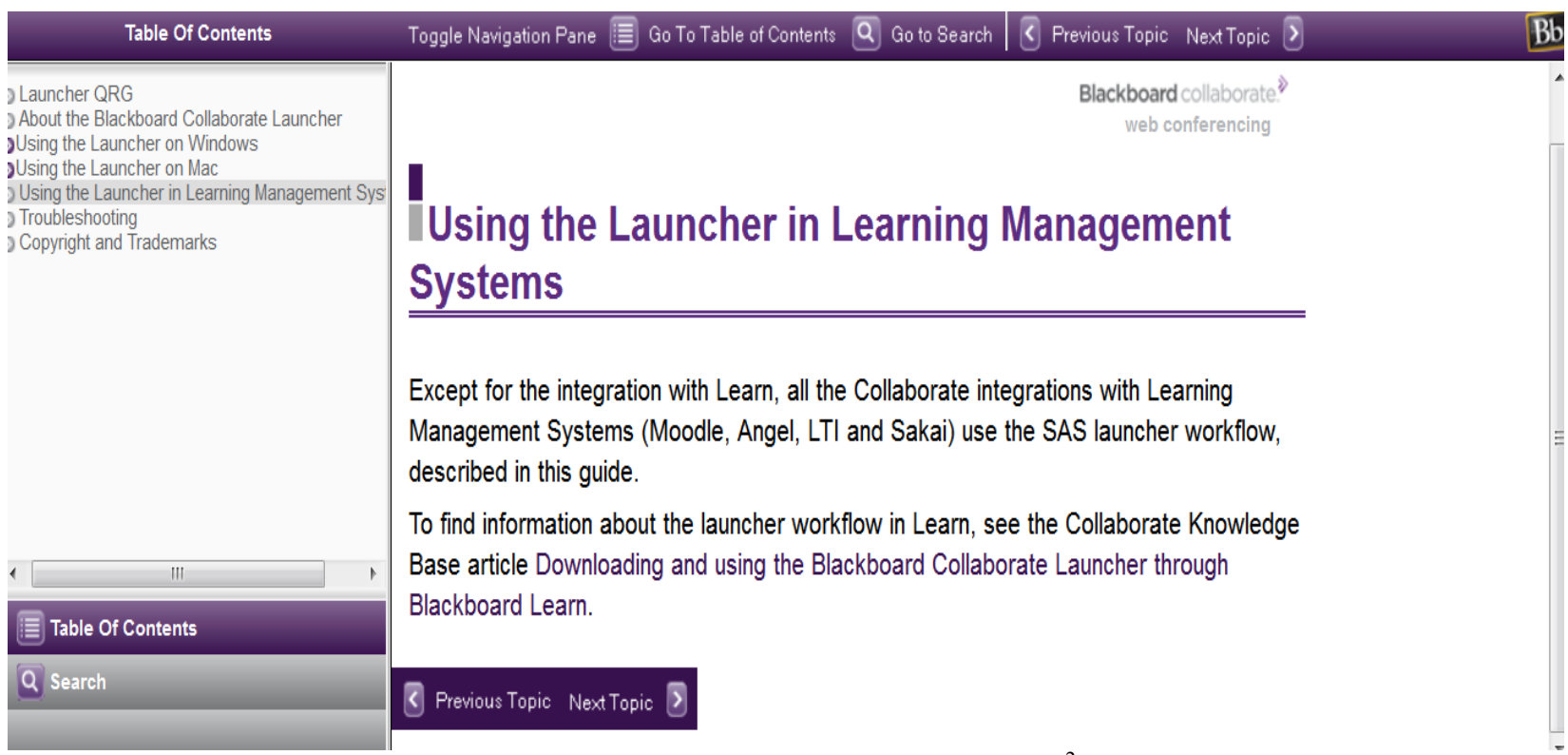

Figure 6: Blackboard (Web Conferencing) ${ }^{2}$ 